\title{
Análisis de Colisión de Principios y Confianza Legítima Frente al Derecho Público
}

\author{
Collision Analysis of Principles and Legitimate Confidence Against Public Law \\ a Iván Rodríguez Lara ${ }^{66}$, Luisa Tamayo Álvarez ${ }^{b}, K_{\text {athy Valencia Pelufo }}{ }^{\mathrm{a}}$ \\ a ivoro2010@gmail.com Estudiante Programa de Derecho, Fundación Universitaria Tecnológico Comfenalco. Cartagena, Colombia. \\ bluisitavarez@gmail.com Estudiante Programa de Derecho, Fundación Universitaria Tecnológico Comfenalco. Cartagena, Colombia. \\ caticaValp@hotmail.com Estudiante Programa de Derecho, Fundación Universitaria Tecnológico Comfenalco. Cartagena, Colombia.
}

Forma de Citar: I. Rodríguez-Lara, L. Tamayo-Álvarez, K. Valencia-Pelufo, “Análisis de Colisión de Principios y Confianza Legítima Frente al Derecho Público”, Rev. Saberes, Vol. 13, No. 02, pp. 99 - 105, 2020.

Recibido: 24/03/2020 Evaluación: 28/05/2020 Aceptado: 30/06/2020 DOI: https://doi.org/10.25213/1794-4384/1302.0014

\begin{abstract}
Resumen
El presente trabajo tiene como objetivo explicar los lineamientos jurisprudenciales entorno a la colisión de los principios de confianza legítima y espacio público, asumiendo como el espacio público es excluyente con el principio de confianza legítima, partir de los análisis desarrolladas por la Corte Constitucional Colombiana, por otro parte se abordará el estudio de la Teoría de los Principios propuesta por Robert Alexis y como los jueces constitucionales en sus jurisprudencias aplicaron la ponderación de principios para resolver esa colisión que se presenta entre estos dos principios consagrados en nuestra Carta Política; la revisión de ordenamiento jurídico de menor rango (Códigos, Leyes Colombianas).
\end{abstract}

\section{Palabras Clave}

Confianza legitima, espacio público, teoría de colisión de principios, derecho al trabajo, informalidad.

\begin{abstract}
The purpose of this work is to explain the jurispru dential guidelines for the collision of the principles of legitimate expectations and space, describing how public space is exclusive to the principle of legitimate expectations, conducting a comprehensive study of the jurisprudence
\end{abstract}

developed by Colombian Constitutional Court where specifically the two variables under study of this project (Right to work vs. the public space and in turn the study of the Theory of Principles proposed by Robert Alexis and as constitutional judges in his jurisprudence applied the weighting of principles to resolve this collision between these two principles enshrined in our Political Charter; revision of lower - ranking legal order (Codes, Colombian Laws) in turn, defining the theory of collision of principles, legitimate trust, public space, the right of work and work under the condition of informality.

\section{Keywords}

Legitimate Trust, public Space, theory of collision of principles, right to work, informality.

\section{Introducción}

La Corte Constitucional Colombiana desde el año de 1992 ha desarrollado en su jurisprudencia los lineamientos a partir de los cuales debe entenderse la latente pugna entre la confianza legítima amparando el derecho al trabajo Vs. La ocupación del espacio público. Es por eso que en este trabajo haremos un análisis entorno a la disputa que se ha venido presentando entre estas dos categorías (Derecho al trabajo Vs. Espacio Público) desde la jurisprudencia Constitucional, teniendo en cuenta el carácter vinculante que esta tiene en el

\footnotetext{
${ }^{66}$ Autor para correspondencia: correo electrónico ivoro2010@gmail.com 
ordenamiento jurídico colombiano; en este sentido surge el siguiente cuestionamiento: ¿Cuáles son los lineamientos jurisprudencia que ha desarrollado la Corte Constitucional colombiana para resolver la colisión entre los principios de confianza legítima en el ejercicio del trabajo y el espacio público?. Cuestionamiento que resolveremos estudiando la teoría de la colisión de principios y como los jueces constitucionales colombianos (Magistrados de la Corte Constitucional Colombiana) resuelven esta colisión de principios entre las dos variables objeto de este investigación: derecho al trabajo (Principio de Confianza legitima) vs. espacio público, describiendo como el espacio público (garantía colectiva - goza de protección constitucional) es excluyente con el principio de confianza legitima que toma como base el principio de buena fe.

\section{Metodología}

El enfoque llevado en esta investigación es jurídico haciendo un estudio amplio de la jurisprudencia desarrolladas por la Corte Constitucional Colombiana donde definen las dos variables objeto de estudio de este proyecto (Derecho al trabajo Vs. el Espacio Público) y a su vez el estudio de la Teoría de los Principios propuesta por Robert Alexis y como los jueces constitucionales en sus jurisprudencias aplicaron la ponderación de principios para resolver esa colisión que se presenta entre estos dos principios consagrados en nuestra Carta Política; la revisión de ordenamiento jurídico de menor rango (Códigos, Leyes Colombianas) a su vez, definiendo la teoría de colisión de principios, confianza legitima (amparada en el derecho al trabajo de los trabajadores informales), espacio público y el análisis de datos estadísticos del DANE.

\section{Resultados}

Posterior del análisis y estudio realizado de las jurisprudencia que los jueces constitucionales ${ }^{67}$, el estudio de la doctrina, ordenamiento jurídico colombiano, datos estadísticos, y la posterior ponderación realizada entre estos dos principios

\footnotetext{
${ }^{67}$ En Colombia magistrados de la Corte Constitucional (corporación que se encargan de dirimir los conflictos surgentes de la incompatibilidad de una ley con la carta política y la salvaguarda de esta misma)
}

objeto de estudio (Confianza Legitima Vs. Espacio Público), el resultado tenido en esta investigación y con el que damos resolución a nuestra pregunta problémica que es: el principio que siempre ha de prevalecer y primar es el espacio público (garantía constitucional y social) sobre la confianza legitima que a su vez debe ser protegido y cuidado por el estado en sus diferentes manifestaciones, realizando planes de reubicación de los trabajadores informales que hacen uso del espacio público (garantía de todos los asociados del Estado Colombiano) en aras de vulnerar los derechos de estos trabajadores y a su vez del resto de asociados del Estado.

El sistema jurídico, no está compuesto únicamente por normas entendidas como reglas, sino también de principio. Las normas por su parte establecen supuestos de hecho y consecuencias jurídicas y en caso de presentarse una colisión entre ellas se resuelven la premisa de la norma posterior y la norma especial. Las normas tipo principios les alude una función tripartita es decir (función triple) que son: 1- De fundamento del ordenamiento Jurídico, 2- De interpretación; es decir como la directriz hermenéutica para la aplicación de las reglas jurídicas y 3- De integración del orden jurídico en caso de falta de norma concreta y específica, son utilizados como fuente integradora del derecho (Sentencia C - 818, 2005, pág. 3) ${ }^{68}$.

La Corte Constitucional Colombia en sentencia $\mathrm{T}$ - 225 de 1992 empieza hablar sobre la confianza legitima en la jurisprudencia de nuestro país, con el fin de dirimir el conflicto jurídico entre el derecho al trabajo de los vendedores ambulantes y el derecho al espacio público, posteriormente esta corporación se vuelve a pronunciar sobre este principio y deja como base de este el principio general de la buena fe (sentencia T-926 de 2010).

El Espacio Público, se encuentra consagrado en nuestra Carta política "Art. 82: Es deber del Estado velar por la protección de la integridad del espacio público y por su destinación al uso común, el cual prevalece sobre el interés particular"

\footnotetext{
${ }^{68}$ La Corte Constitucional de Colombia, en Sentencia C - 818 de 2005 en la pág. 3 describe las funciones normativas de los principios en el ordenamiento jurídico.
} 
(Constitucion Politica de Colombia, 1991)"69, es decir que el espacio público son todos los bienes de uso público destinado para el goce y disfrute de los ciudadanos como calles, parques, plaza etc. La Corte Constitucional en sentencia T - 372 de 1993 ha dicho que es deber del Estado velar por la protección y recuperación de este mismo.

El principio de la confianza legítima ha sido ampliamente invocado y desarrollado jurisprudencia de la corte constitucional para dirimir en la colisión entre el derecho al trabajo y al espacio público.

\section{¿Cuándo Existe la Colisión de Principios?}

Existe cuando en un caso concreto, son relevantes dos o más disposiciones judiciales, las cuales podrían ser respuesta cada una al caso concreto. Para aplicar y resolver esta colisión que se presenta entre principios, Robert Alexi planteo la teoría de la ponderación, que consiste en asignar un peso a cada principio que entran en colisión dentro de un caso concreto y determinar qué principio precede sobre el otro, el principio que quede desplazado no queda invalido, pero en ese caso concreto no es aplicable ya que será aplicable el de mayor peso (prevalencia condicionada).

En la problemática planteada en este proyecto de investigación (trabajo informal), los principios que entran en colisión (colisión de principios que en reiteradas ocasiones la Corte Constitucional Colombiana que por vía jurisprudencial ha resuelto) son: principio de confianza legitima sustentado en el derecho al trabajo vs. el espacio público que es una garantía colectiva que todos como asociados del estado colombiano tenemos y además goza de protección constitucional.

Previo al análisis de la colisión de principios que son objeto de estudio de este trabajo (confianza Legítima vs. espacio público) definiremos cada uno de estos principios:

Confianza Legítima. Es el limite a las actividades de las autoridades, que pretende hacerles frente a eventuales modificaciones intempestivas en su manera tradicional de proceder, situación que además puede poner en riesgo el principio de

\footnotetext{
${ }^{69}$ Constitución promulgada por el Congreso de la Republica de Colombia después de la ANAC (Asamblea Nacional Constituyente) de 1991.
}

seguridad jurídica. "Se trata pues, de un ideal ético que es jurídicamente exigible, El principio de la confianza legítima es un corolario de aquel de la buena fe y consiste en que el Estado no puede súbitamente alterar unas reglas de juego que regulaban sus relaciones con los particulares, sin que se les otorgue a estos últimos un periodo de transición para que ajusten su comportamiento a una nueva situación jurídica. No se trata, por tanto, de lesionar o vulnerar derechos adquiridos, sino tan sólo de amparar unas expectativas válidas que los particulares se habian hecho con base en acciones $u$ omisiones estatales prolongadas en el tiempo, bien que se trate de comportamientos activos o pasivos de la administración pública, regulaciones legales o interpretaciones de las normas jurídicas. De igual manera, como cualquier otro principio, la confianza legítima debe ser ponderada, en el caso concreto, con los otros, en especial, con la salvaguarda del interés general y el principio democrático. [...] (Constutitucional, 2004 pag. 3) ${ }^{70}$.

El principio de confianza legítima, pese a no estar consagrado expresamente en la constitución colombiana, tiene validez dentro de nuestro ordenamiento jurídico, puesto que se encuentra fundamentada en dos disposiciones constitucionales: el principio de la buena fe y el principio de seguridad jurídica, implícito en el artículo 1 de la constitución política, que contiene la cláusula del estado de derecho, este principio ha tenido un desarrollo en la jurisprudencia colombiana ya que ha sido el mecanismo idóneo para dirimir muchos conflictos jurídico, tales como los vendedores informales, donde se presenta conflictos entre el derechos al trabajo y la recuperación del espacio público. No siendo el principio de la confianza legítima de carácter absoluto, deberá este someterse a ponderación con los demás principios que colisione, ejemplo de ellos se tiene el principio del interés general, el espacio público y el de derecho al trabajo. Se comprende que existe confianza legítima cuando se demuestra que las actuaciones u omisiones de la administración anteriores a la orden de desocupar les permitía concluir que su conducta era jurídicamente aceptada. En estos escenarios se

\footnotetext{
${ }^{70}$ Criterio expuesto por la Corte Constitucional Colombia en la Sentencia C-131 de 2004 pág. 3.
} 
deben ponderar, proporcional $\mathrm{y}$ armoniosamente, los derechos a la defensa del espacio público y al trabajo amparados por la confianza legítima.

Espacio Público. "Art. 5. Entiéndese por espacio público el conjunto de inmuebles públicos y los elementos arquitectónicos y naturales de los inmuebles privados, destinados por su naturaleza, por su uso o afectación, a la satisfacción de necesidades urbanas colectivas que transcienden, por tanto, los límites de los intereses, individuales de los habitantes (Gestor Normativo, 1989) ${ }^{71}$ ". La corte constitucional colombiana define claramente el espacio público es una subcategoría de los bienes de uso público, que cuentan con un ordenamiento jurídico fundamentado en la constitución política y que está reglamentado por las leyes y actos administrativos tanto a nivel nacional como local.

Colisión de principios. Esta pugna entre la confianza legítima y el espacio público se ha desarrollado a nivel nacional debido a que los vendedores informales utilizan el espacio público para poder desarrollar ventas comerciales y con la garantía de la confianza legítima, en el espacio público, la corte constitucional se ha pronunciado al respecto. Por tanto, la ponderación erige como el mecanismo de enfrentamiento entre dos principios cuyo fin es que uno ceda en favor de otro, otorgando lemas poder o más validez en un caso concreto.

$\mathrm{Al}$ respecto Robert Alexis, expone tres pasos para lograr la ponderación: el primero, es definir el grado de satisfacción de uno y el grado de afectación de otro, el segundo, hace referencia a la importancia de afectarlo o satisfacer uno y otro, y el ultimo, hace referencia de satisfacer uno sobre la afectación de otro.

Entonces le surge a la administración la obligación de someter a consideración cada una de las decisiones administrativas según el caso concreto, $\mathrm{y}$ determinar la justificación de restringir el principio de la confianza legítima, o su no justificación y la prevalencia por supuesto del principio. En definitiva, tal como lo ha manifestado la corte constitucional, el principio de

\footnotetext{
${ }^{71}$ Art. 5 de la Ley $9^{\text {a }}$ de 1989 , ley por la cual se dictan las normas de desarrollo municipal, compraventa y expropiación de bienes y se dictan otras disposiciones en Colombia.
}

confianza legítima como cualquier otro principio debe ser ponderada, en el caso concreto, con los otros en especial, con la salvaguarda del interés general y el principio democrático. Esta pugna que se presenta entre estos dos principios que se ha venido generado con los años, ya que en este se da el trabajo informal (amparado en el principio de la confianza legitima) que es la forma como parte de la población desempleada en Colombia obtienen sus ingresos, que para el trimestre de Julio a septiembre de 2019 estuvo en un 43, 6\% para los hombres y $48,3 \%$ en el caso de las mujeres según fuentes del DANE ${ }^{72}$.

La Corte Constitucional en Colombia, en su jurisprudencia ha establecido los lineamientos con los cuales se resuelven la colisión entre estos dos principios (Confianza Legitima Vs. Espacio Público). La Corte en sentencias SU 360 y 601 de 1991 enfoco su criterio en que la confianza legitima no puede ser un obstáculo para tutelar el derecho constitucional al espacio público, y es deber del estado velar por su protección y destinación común desarrollando planes de reacomodación de los distritos y municipios para reubicarlos sin que se les vulneren sus derechos. En sentencia T - 772 del 2003 esta corporación afirma que las autoridades tienen el deber y la potestad de adelantar políticas, programas y medidas orientadas a recuperar y preservar el espacio público, respetando el debido proceso, la confianza legitima y no se pueden adelantar estos programas en forma que se vulneren sus derechos. En sentencia SU - 601 de 1999, la corte define el principio de confianza legitima como el mecanismo para conciliar el interés general que se concreta en el deber de la administración de conservar y preservar el espacio público y, de otro lado, los derechos al trabajo e igualdad de las personas que ejercen el comercio informal, en sentencia T - 926 de 2010 conceptúa que este principio (confianza legitima) impone al estado el deber de respetar las expectativas favorables que $\mathrm{su}$ actuación $\mathrm{u}$ omisiva ha generado en los vendedores informales, respecto de la perdurabilidad del desarrollo del ejercicio de sus actividades laborales en el espacio público.

\footnotetext{
72 El DANE, es el Departamento Administrativo Nacional de Estadísticas en Colombia, es la entidad que se encarga de planificar y realizar las estadísticas a nivel nacional por todo el territorio.
}

Página | 102 
El principio de confianza legitima se deriva del art. 83 (de la Carta Política) superior al estatuir que las actuaciones de los particulares y de las autoridades deberán ceñirse a los postulados de la buena fe, la cual se presumirá, la cual se presumirá en todas las gestiones que aquellos adelantan ante estas, tal norma constitucional ha sido desarrollada por esta corporación, indicando que las relaciones con la comunidad han de ceñirse a ese principio (Sentencia T - 097 de 2011). También, esta corporación (Corte Constitucional) ha indicado que es deber de la administración actuar en sus relaciones jurídicas con los particulares de manera consecuente con sus conductas precedentes, de manera que los administrados no se vean sorprendidos con conductas contrarias a sus expectativas legítimamente fundadas, basado como está el principio de confianza legítima en que las autoridades no puedan alterar, en forma inopinadas, las reglas que gobiernan las relaciones del estado con los asociados, la corte reitera este mismo concepto en las sentencias T - 244 de 2012 y $\mathrm{T}-386$ de 2013.

La corte constitucional estableció que: "en el ejercicio del deber estatal de recuperación del espacio público, las autoridades no pueden vulnerar el principio de confianza legítima, ni el derecho al trabajo y la dignidad humanan de los comerciantes informales que lo ocupan (Sentencia T - 243 de 2019)". También ha dicho esta corporación, que: "El conflicto entre el deber del Estado de recuperar y proteger el espacio público, el derecho al trabajo ha sido resuelto en favor del primero de éstos, por el interés general en que se fundamenta. Pero se ha reconocido, igualmente, que el Estado en las políticas de recuperación de dicho espacio, debe poner en ejecución mecanismos para que las personas que se vean perjudicadas con ellas puedan reubicar sus sitios de trabajo en otros lugares. Del libre ejercicio del derecho fundamental al trabajo depende la subsistencia de las familias de los vendedores ambulantes. Sin embargo, la ocupación del espacio público no está legitimada por la Constitución (Sentencia T / 372 de 1993)".

La obligación de las autoridades distritales de ofrecer alternativas económicas a los vendedores informales cuando se realicen campañas de restablecimiento del espacio público de la siguiente manera: Las autoridades distritales competentes están en el deber constitucional de incorporar, como parte integrante de dichas políticas, programas o medidas de recuperación del espacio público, un componente obligatorio de provisión de alternativas económicas para quienes dependen del comercio informal para su sustento vital, el cual se debe haber formulado con base en una evaluación $\mathrm{y}$ un seguimiento previos $\mathrm{y}$ detallados de las condiciones sociales y económicas reales y cambiantes de la capital, con miras a asegurar el goce efectivo de los derechos fundamentales fue introducida a la jurisprudencia mediante la sentencia $\mathrm{T}-722$ de 2013.

La Corte Constitucional, resuelve esta colisión (confianza legitima vs. espacio público) aplicando la teoría de la ponderación propuesta por Robert Alexi, que consiste en asignarle un peso a cada principio y determinar la relación de prevalencia de uno de estos en un caso concreto, en este sentido la Corte Constitucional resolvió esta colisión en la cual el principio que prevaleció fue el Espacio público garantía que goza de protección constitucional sobre el derecho al trabajo que tienen los vendedores ambulantes y el Estado no puede desconocer que lo hacen con el fin de conseguir medios efectivos que aseguren su mínimo vital y les permitan la realización de otros derechos fundamentales. (Corte Constitucional, Sentencia T 904 de 2012).

\section{Conclusión}

La defensa del derecho constitucional al espacio público es jurídicamente exigible. La competencia, para ese efecto, es de las autoridades administrativas y judiciales, quienes tienen la obligación de ejercer vigilancia y garantizar su protección. Quienes ejercen el comercio o son trabajadores informales en estas zonas hacen uso de su derecho al trabajo, el cual también goza de protección constitucional cuando se fundamenta en la confianza legítima.

Muy a pesar que la Corte Constitucional Colombiana ha tenido un desarrollo jurisprudencial amplio, suficiente y vinculante, sobre cómo resolver la colisión de principios surgida entre la confianza legitima (que proclaman los vendedores ambulantes) y el espacio público (garantía social y constitucional) en la que el resultado es la primacía del espacio público sobre la confianza legítima atribuida a los vendedores ambulantes sin descartar el derecho al trabajo que 
tienen estos vendedores por parte de las autoridades al momento de llevar a cabo los planes de reubicación y así garantizar que estos derechos no se vulneren entre sí.

\section{Referencias Bibliográficas}

Alcaldía mayor de Bogotá. (2016). Peñalosa ha liderado 150 operativos para recuperar el espacio público en Bogotá. Recuperado en: http://www.bogota.gov.co/content/temas-deciudad/gobiernoseguridad-yconvivencia/penalosa-ha-liderado-150operativos-para-recuperar-espacio-publico

García, D. (2015). Espacio público y comercio en la ciudad contemporánea. Dearq. Revista de Arquitectura (17). Universidad de los Andes. Recuperado en: https://revistas.uniandes.edu.co/doi/ref/10.18389/ dearq17.2015.02

Alcaldía mayor de Bogotá. (2017). Más de 3.000 vendedores informales han aceptado los planes de reubicación de la Alcaldía Peñalosa. Recuperado en: $\quad$ http://bogota.gov.co/content/temasdeciudad/desarrollo-economico/mas-de-3000vendedores-informales-han-aceptado-planes$\underline{\text { dereubicacion-de-alcaldia }}$

Ardila, I, Hoyos, O y Sabogal, D, (2010). Las prácticas de mercadeo intuitivo en el turismo popular. Perfiles Libertadores, 19 (33), p.131-153.

Borja, H., Barreto, I. y Sánchez, V. (2008). Actitudes del vendedor ambulante de la localidad de Chapinero frente a sus condiciones laborales y políticas. Diversitas: Perspectivas en Psicología, 4(2), 279-290.

Camargo, D. (2005). Actividades económicas informales y tributación, p.75.Edición electrónica a texto completo en www.eumed.net/libros/2005/dfch-eva/

Caldas, S. (2010). Nivel de disposición de los vendedores ambulantes para la formalización de sus negocios en la ciudad de Bogotá D.C (Tesis de pregrado). Universidad pontificia Javeriana. Bogotá, Colombia.
DANE. (2017). Boletín técnico. Medición de empleo informal y seguridad social: trimestre móvil marzo-mayo de 2017. Recuperado en: https://www.dane.gov.co/files/investigaciones/bol etines/ech/ech_informalidad/bol_ech_informalida d mar17 may17.pdf

Castillo, L. (2005). ¿Existen los llamados conflictos entre los Derechos fundamentales? Cuestiones constitucionales Revista mexicana de derecho constitucional. 1(12). p.1-4.

PARRA, O. (2006). De la ciudadanía autoritaria a una ciudadanía social diferenciada y participativa. Apuntes sobre el debate vendedores ambulantesespacio público. Revista Estudios Políticos, 28, pp. 3159 .

PIÑA, A. (2010). Politización de las ventas ambulantes en Bogotá. Universidad Católica de Colombia Revista de Arquitectura, 12, 4-16.

ROCHA, R, Sánchez, F, García, L. (2009). Ventas callejeras y espacio público: efectos sobre el comercio en Bogotá. Revista Desarrollo y sociedad, p.245-268.

https://www.funcionpublica.gov.co/eva/gestornor mativo/norma.php?i=1175

http://www.secretariasenado.gov.co/senado/based oc/codigo_sustantivo trabajo.html

www.constitucioncolombia.com, titulo-2, capitulo-3 > articulo-82

Corte Constitucional, Sala quinta de revisión (16 de marzo de 1995) Sentencia T-115 de 1995. (M.P José Gregorio Hernández Galindo).

Corte Constitucional, Sala séptima de revisión (25 de agosto de 1997) Sentencia T- 398 de 1998 (M.P. Alejandro Martínez Caballero).

Corte Constitucional, Sala primera de revisión (3 de septiembre de 1993) Sentencia T- 372 de 1993 (M.P Jorge Arango Mejía).

Corte Constitucional, Sala octava de revisión (29 de abril de 1996) Sentencia T-160 de 1996 (M.P. Fabio Morón Díaz). 
Corte Constitucional, Sala octava de revisión (20 de agosto de 2003) Sentencia T-722 de 2003 (M.P. Álvaro Tafur Galvis).

Corte Constitucional, Sala séptima de revisión (2 de noviembre de 2012) Sentencia T- 904 de 2012 (M.P. Jorge Ignacio Pretelt).

Corte Constitucional, Sala séptima de revisión (26 de marzo de 2012) Sentencia T-244 de 2012 (M.P. Jorge Ignacio Pretelt).

Corte Constitucional, Sala Plena de la Corte Constitucional (09 de agosto de 2005) Sentencia C - 818 de 2005 (M.P. Rodrigo Escobar Gil).

Corte Constitucional, Sala séptima de revisión (25 de septiembre de 2007) Sentencia T-773 de 2007 (M.P. Humberto Antonio Sierra Porto).

Corte Constitucional, Sala tercera de revisión (4 de septiembre de 2003) Sentencia - 772 de 2003 (M.P. Manuel José Cepeda Espinosa). 